\title{
A medium frequency transformer with multiple secondary windings for medium voltage converter based wind turbine power generating systems
}

Md Rabiul Islam, Youguang Guo, and Jianguo Zhu

Citation: Journal of Applied Physics 113, 17A324 (2013);

View online: https://doi.org/10.1063/1.4795850

View Table of Contents: http://aip.scitation.org/toc/jap/113/17

Published by the American Institute of Physics

\section{Articles you may be interested in}

An amorphous alloy core medium frequency magnetic-link for medium voltage photovoltaic inverters Journal of Applied Physics 115, 17E710 (2014); 10.1063/1.4864050

Oxygen-vacancy effect on structural, magnetic, and ferroelectric properties in multiferroic $\mathrm{YMnO}_{3}$ single crystals Journal of Applied Physics 111, 07 D913 (2012); 10.1063/1.3676000

Isotopic exchange in gamma-irradiated mixtures of $\mathrm{C}_{24} \mathrm{H}_{50}$ and $\mathrm{C}_{24} \mathrm{D}_{50}$ : Evidence of free radical migration in the solid state

The Journal of Chemical Physics 87, 1588 (1998); 10.1063/1.453218

Influence of electron beam irradiation on the microrheology of incompatible polymer blends: Thread break-up and coalescence

Journal of Rheology 35, 63 (1998); 10.1122/1.550209

\section{Scilight}

Sharp, quick summaries illuminating the latest physics research

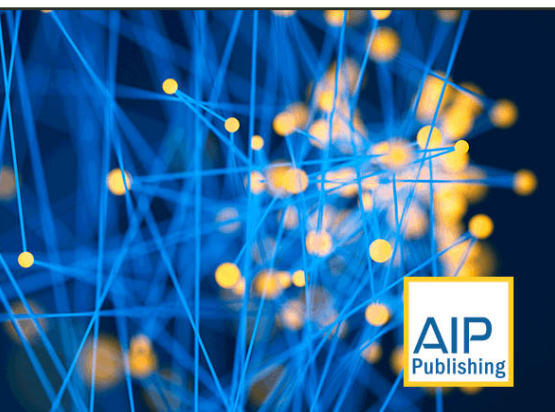




\title{
A medium frequency transformer with multiple secondary windings for medium voltage converter based wind turbine power generating systems
}

\author{
Md Rabiul Islam, ${ }^{\text {a) }}$ Youguang Guo, and Jianguo Zhu \\ Centre for Electrical Machines and Power Electronics, University of Technology Sydney, 15 Broadway, \\ Ultimo, NSW-2007, Australia
}

(Presented 16 January 2013; received 30 October 2012; accepted 14 December 2012; published online 22 March 2013)

\begin{abstract}
Recent advances in magnetic materials have led to the development of compact and light weight, medium and high frequency transformers, which would be a possible solution to reducing the size and weight of wind turbine power generating systems. This paper presents the overall design and analysis of a Metglas amorphous alloy 2605SA1 based medium frequency transformer to generate the isolated balanced multiple DC supplies for medium voltage converter systems. A comprehensive electromagnetic analysis is conducted on the proposed design based on experimental results. The test stand, data analysis, and test results are discussed. (c) 2013 American Institute of Physics. [http://dx.doi.org/10.1063/1.4795850]
\end{abstract}

\section{INTRODUCTION}

The power generated by most commonly used wind turbine generators is at low voltage levels of $380-690 \mathrm{~V} .{ }^{1}$ To reduce the electrical power transmission losses, a low frequency transformer is usually used to step-up the voltage up to the voltage levels of $11-33 \mathrm{kV}$. This heavy and bulky low frequency transformer significantly increases the weight and volume of the nacelle as well as the mechanical stress of the tower. The weight and volume of a $33 / 0.69 \mathrm{kV}, 2.6 \mathrm{MVA}$ transformer is typically in the range of 6-8 tons and 5-9 $\mathrm{m}^{3}$, respectively. ${ }^{2}$ Hence, a step-up transformer-less, medium voltage converter based high power density nacelle would be an attractive technology for the future wind turbine systems.

The series connected H-bridge (SCHB) topology has gained popularity for the medium voltage applications. ${ }^{3,4}$ However, the SCHB converter requires multiple-isolated and balanced DC sources. To couple the wind turbine generator to the multi-level SCHB converter, a medium-frequency transformer with multiple secondary windings is developed and reported in this paper. Compared with the conventional transformers operated at the power frequency $(50$ or $60 \mathrm{~Hz})$, the medium frequency (in the range of a few $\mathrm{kHz}$ to $\mathrm{MHz}$ ) transformers have much smaller and lighter magnetic cores and windings, and, thus, much lower costs. The proposed medium frequency transformer-link based wind turbine power generating systems will have the following advantages: (i) inherent DC-link voltage balancing due to single DC supply, (ii) compact and light overall system, and (iii) simple installation and low maintenance cost.

\section{DESIGN AND CONSTRUCTION OF MEDIUM FREQUENCY TRANSFORMER}

In transformer design, because the winding electromotive force (emf) is proportional to the number of turns, frequency, and magnetic flux linking the winding, for a given

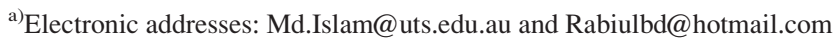

power capacity; as the operating frequency increases, the required cross sectional area of magnetic core and the number of turns of the primary and secondary windings can be dramatically reduced. To verify the feasibility of the new concept of voltage step-up using the SCHB converters, in this paper, a $1.26 \mathrm{kVA} 10 \mathrm{kHz}$ transformer-link prototype with 6 secondary windings is developed to generate the isolated and balanced 6 DC supplies for a 5 level SCHB converter, which would convert $216 \mathrm{~V}$ DC into 3 phase $1 \mathrm{kV}$ rms AC. The same concept can be used to model the practical system by only changing the number of secondary windings as well as the number of levels of the converter.

The grain oriented silicon sheet steels, which are commonly used as the core material for power frequency transformers, are not suitable for medium frequency applications because of the heavy eddy current loss. ${ }^{5}$ The soft ferrites have been widely used in medium and high frequency inductors and transformers due to the low price and general availability. Because of the low saturation flux density (only 0.3 to $0.5 \mathrm{~T}$ ), ${ }^{5}$ which would make the transformer bulky, they are not suitable for large power applications. On the other hand, the amorphous alloy and nanocrystalline materials have excellent magnetic characteristics for medium frequency applications, such as high permeability, high saturation flux density, and relatively low core losses. The nanocrystalline alloy Vitroperm $55 \mathrm{Z}$ has lower specific core loss than that of Vitroperm 500F. Of the other amorphous alloys 2605SA1 and 2605S3A, the alloy 2714A has the lowest specific core loss but its saturation flux density is only $0.57 \mathrm{~T} .^{6}$ Although nanocrystalline alloy has lower specific core loss than amorphous alloy, its saturation flux density (about $1 \mathrm{~T}$ ) is much lower than that of amorphous alloy 2605SA1, which is $1.56 \mathrm{~T}$. Up to now many kinds of soft magnetic alloys with high magnetic flux density combined with low core loss have been developed. ${ }^{7,8}$ Taking into account the flux density, specific core loss, cost, and availability, we chose Metglas 2605SA1 stripe of $30 \mu \mathrm{m}$ thickness and $25 \mathrm{~mm}$ width as the core material. The other parameters are mass density of $7.18 \mathrm{~g} / \mathrm{cm}^{3}$, saturation flux density of $1.56 \mathrm{~T}$, 


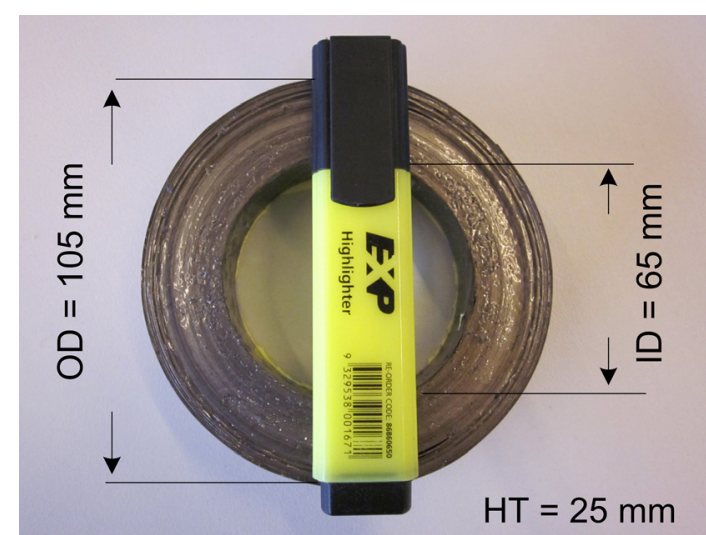

FIG. 1. Photo of the transformer core, where OD is the outer diameter, ID the inner diameter, and HT the height.

and specific core loss of $180 \mathrm{~W} / \mathrm{kg}$ at $10 \mathrm{kHz}$ sinusoidal excitation of $1 \mathrm{~T}^{9}$

The Metglas sheet was glued with Araldite on the surface of each layer, providing both the electrical insulation and mechanical bonding. The core volume and mass are $133.52 \mathrm{~cm}^{3}$ and $0.96 \mathrm{~kg}$, respectively. Figure 1 shows a photo of the Metglas core. To minimize the proximity effect, Litz wires are used for windings with single layer placement as shown in Figure 2. The electromagnetic performances were analyzed and compared with the experimental results in Sec. III.

\section{EXPERIMENTAL TESTING AND RESULTS ANALYSIS}

The transformer is excited by a $10 \mathrm{kHz}$ square wave primary voltage, which is generated by an insulated gate bipolar transistor (IGBT) based H-bridge inverter supplied by a 216 V DC voltage source. According to Faraday's law, the flux density waveform is triangular. If $f$ is the excitation frequency, $B_{\text {max }}$ is the maximum flux density, and $A$ is the cross sectional area of the transformer core, then the number of turns of a winding can be deduced as

$$
N=\frac{V_{r m s}}{4 f B_{\max } A} .
$$

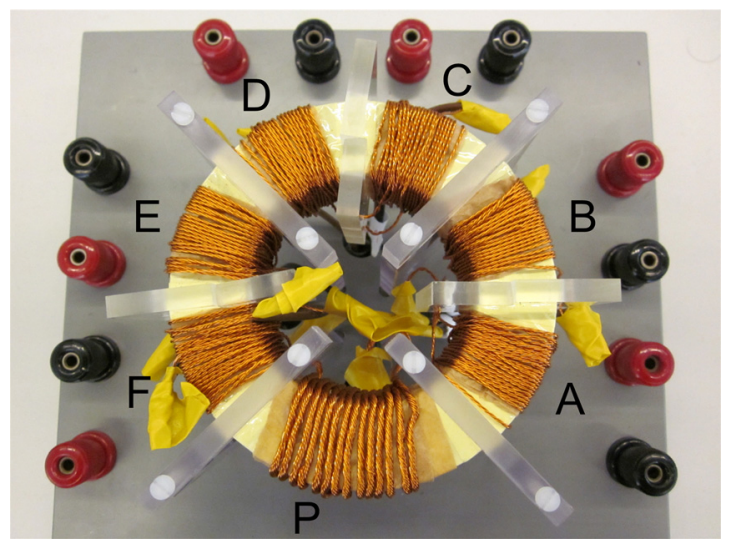

FIG. 2. Photo of transformer, where $P$ is the primary coil and A-F the 6 secondary coils.

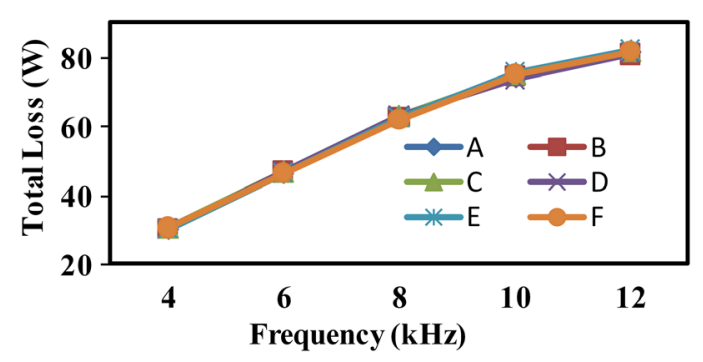

FIG. 3. Measured total losses against excitation frequencies at excitation current of $0.5 \mathrm{~A}$; only one coil is energized at a time while others open circuited.

The theoretical result of voltage transformation ratio, which is calculated as 1.781 , was verified by measuring the voltage transformation ratios of all 6 secondary windings versus the primary, and they were found highly consistent with the theoretical value (variation less than $\pm 0.3 \%$ ). This is obligatory for the SCHB converter system.

An Agilent Technologies DS06034A oscilloscope with P5200 high voltage differential probe and Tektronix TCPA300 current probe was used to observe the voltage and current waveforms. The total loss (core loss plus copper loss) was measured by a Voltech PW3000A universal power analyzer. From the oscilloscope data, the copper loss of each winding at different frequency ranging from 4 to $12 \mathrm{kHz}$ was calculated by using the DC resistances $(0.024 \Omega$ for the primary and $0.16 \Omega$ for the secondary), since the AC/DC resistance ratios, $K r$, in this design is almost unity due to the use of Litz wires.

In a conductor, the ratio $K r$ depends strongly on both the number of layers and the conductor diameter (Ref. 10). It shows that at medium or high frequencies, associated with a small skin depth and proximity effect, the number of layers as well as conductor diameter should be kept as small as possible. Moreover, the insulated strands should be twisted or braided together to equalize the flux linkages throughout the conductors. To achieve this, so as to reduce the winding loss a Litz wire with small number of layers should be always used in a medium-frequency power transformer.

Figure 3 shows that the total losses of all secondary windings measured at different excitation frequencies ranging from 4 to $12 \mathrm{kHz}$ are almost the same. Measurements were also conducted by exciting the secondary windings one by one with different excitation currents $(0.1-0.6 \mathrm{~A})$ and a fixed frequency of $10 \mathrm{kHz}$. As shown in Figure 4, at $10 \mathrm{kHz}$, all secondary windings have also very similar total losses. Such similarity of characteristics is also obligatory to generate balanced multiple sources for the SCHB system.

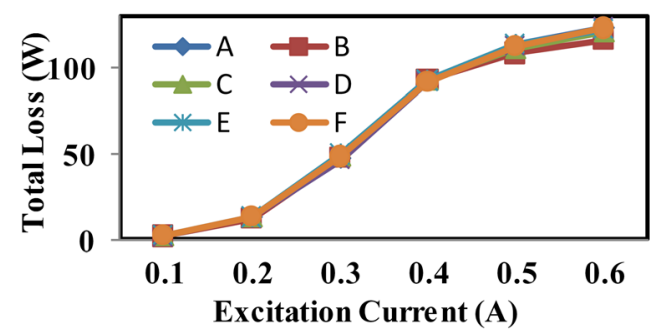

FIG. 4. Measured total losses against excitation currents of $10 \mathrm{kHz}$; only one coil is energized at a time while others open circuited. 


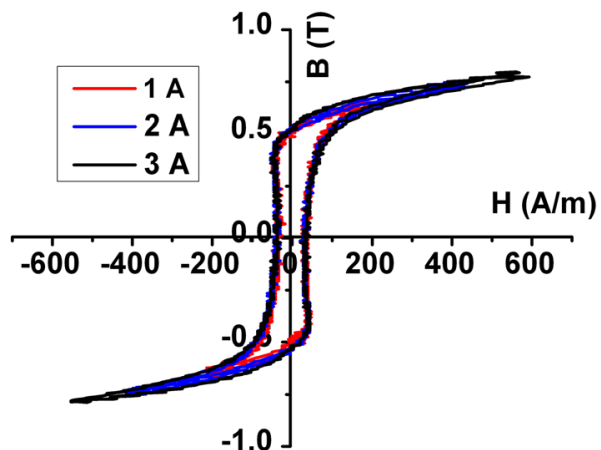

FIG. 5. Measured B-H curves at $40^{\circ} \mathrm{C}$ : maximum magnetic flux density at 1,2 , and $3 \mathrm{~A}$ is $0.65,0.74$, and $0.80 \mathrm{~T}$, respectively.

The magnetic field intensity and magnetic flux density are calculated by measuring the P-coil excitation voltage and current and the open circuit terminal voltage of the secondary side D-coil. As the coils are uniformly wound on the toroidal core, the magnetic field intensity $H$ and magnetic flux density $B$ within the core can be considered as uniform. By Ampere's law, the field intensity can be calculated as

$$
H=\frac{N_{1} i(t)}{l_{e}},
$$

where $N_{l}$ is the number of turns in the primary coil, $i(t)$ is the excitation current, and $l_{e}$ is the mean length of the core. By Faraday's law, the magnetic flux density in the core can be calculated as

$$
B=\frac{1}{N_{2} A_{e}} \int V_{L} d t
$$

where $N_{2}$ is number of turns in the pick-up coil (D-coil), $A_{e}$ is the cross sectional area of the core, and $V_{L}$ is the pick-up coil voltage.

Different magnitudes of $10 \mathrm{kHz}$ excitation currents (1-3 A) are applied to the primary windings. $B-H$ curves are plotted based on experimental data. Up to $0.5 \mathrm{~T}$, the flux density rises sharply with a constant field intensity of about $50 \mathrm{~A} / \mathrm{m}$ as shown in Figure 5. At $3 \mathrm{~A}$, the maximum magnetic flux density is about $0.8 \mathrm{~T}$ with the field intensity of about $600 \mathrm{~A} / \mathrm{m}$ which satisfies the design. $B-H$ curves are

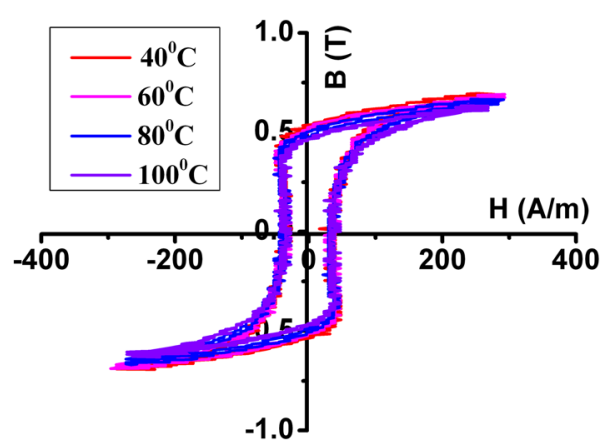

FIG. 6. Measured B-H curves at different temperature ranging from $40^{\circ} \mathrm{C}$ to $100^{\circ} \mathrm{C}$ : maximum magnetic flux density at $40^{\circ} \mathrm{C}, 60^{\circ} \mathrm{C}, 80^{\circ} \mathrm{C}$, and $100^{\circ} \mathrm{C}$ is $0.65,0.65,0.64$, and $0.63 \mathrm{~T}$, respectively.

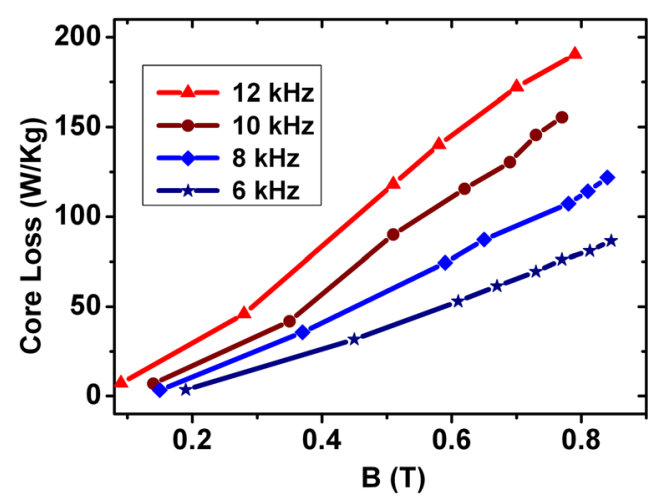

FIG. 7. Measured core losses at different frequency ranging from $6 \mathrm{kHz}$ to $12 \mathrm{kHz}$; experiments were carried out at $40^{\circ} \mathrm{C}$.

also analyzed at different temperatures ranging from $40^{\circ} \mathrm{C}$ to $100^{\circ} \mathrm{C}$. The maximum flux density remains approximately constant for this temperature range, as illustrated in Figure 6. The plotted $B-H$ curves have been compared with the material manufacturer's data and found highly consistent. The core loss against flux density was measured within the frequency range from $6 \mathrm{kHz}$ to $12 \mathrm{kHz}$. The specific core loss measured was $157 \mathrm{~W} / \mathrm{kg}$ under $10 \mathrm{kHz}$ square wave excitation of magnitude $0.8 \mathrm{~T}$ as shown in Figure 7, while the specific core loss of $125 \mathrm{~W} / \mathrm{kg}$ is reported by the material manufacturer under $10 \mathrm{kHz}$ sinusoidal excitation of magnitude $0.8 \mathrm{~T}$. In comparison with material manufacturer's data, about $20 \%-30 \%$ extra loss is observed due to non-sinusoidal excitation waveform. ${ }^{10}$ The output of each secondary winding is connected to a fast recovery diode based rectifier with a low pass RC filter circuit. The DC-link voltages were found approximately equal at about $370 \mathrm{~V}$, which can serve satisfactorily as the isolated and balanced DC sources for the proposed SCHB converter.

\section{CONCLUSION}

The proposed amorphous alloy based medium frequency transformer-link can be a good solution to provide multiple isolated and balanced DC supplies for the SCHB converter to step-up the low voltage of a commercially available wind generator to medium 3 phase AC voltage suitable for power transmission from remote (e.g., off-shore) wind farms to the main grid transmission lines. Without the heavy and bulky low frequency step-up transformer, the proposed architecture leads to a compact and light weight environmentally friendly design, which may save large amount of installation, running and maintenance costs of off-shore wind turbine power generating systems.

${ }^{1}$ X. Yuan et al., IEEE Trans. Sustainable Energy 3, 318 (2012).

${ }^{2}$ M. R. Islam et al., in Proceedings of the 2012 Australasian Universities Power Engineering, Bali, Indonesia, 2012.

${ }^{3}$ Z. Wang et al., IEEE Trans. Magn. 48, 4530 (2012).

${ }^{4}$ M. R. Islam et al., in Proceedings of 14th ICEMS, Beijing, China, 2011.

${ }^{5}$ E. Agheb et al., Sustainable Energy 4, 033113 (2012).

${ }^{6}$ R. Burdt et al., J. Appl. Phys. 99, 08D911 (2006).

${ }^{7}$ Z. Zhang et al., J. Appl. Phys. 112, 103902 (2012).

${ }^{8}$ A. Makino et al., J. Appl. Phys. 109, 07A302 (2011).

${ }^{9}$ Metglas, Inc., see http://metglas.com for 2605SA1 Technical Bulletin.

${ }^{10}$ M. Sippola et al., IEEE Trans. Power Electron. 17, 835 (2002). 